\title{
Introduction: Implications of Citizenship Acquisition
}

\author{
Pieter Bevelander • Ravi Pendakur
}

Published online: 28 July 2011

(C) Springer Science+Business Media B.V. 2011

\section{Introduction}

In an era where there is increasing immigration and increasing diversity, and concomitantly, a policy era where countries in North America and Europe seek to tighten citizenship acquisition rules, it is important to understand the social, economic, and legal implications associated with naturalization. The goal of this special issue is to explore citizenship issues across a broad range of both countries and issues. The five papers in this issue are drawn from a 2-day conference on citizenship issues held in Malmo, Sweden in May of 2009. The conference, co-funded by the International Migration Integration and Social Cohesion project and Malmo Institute for Studies of Migration Diversity and Welfare brought together a multidisciplinary group of researchers from Europe, Canada, and Turkey to share research on the implications of citizenship acquisition at both the micro and macro scale.

\section{Importance of Citizenship}

The increasing pressure of international migration has brought the issue of noncitizen participation to center stage in most countries' political agendas. Countries in both North America and Europe are facing the challenge of regulating the inclusion of newcomers within their diverse societies and encouraging the growth of social cohesion. The central theme of this special issue is to understand the social, economic, and political determinants and consequences of citizenship acquisition for migrants. This knowledge in turn could provide some understanding of the causes

\footnotetext{
P. Bevelander $(\bowtie)$

Malmö University, Malmö, Sweden

e-mail: Pieter.Bevelander@mah.se

R. Pendakur

University of Ottawa, Ontario, Canada

e-mail: Pendakur@uottawa.ca
} 
and provide some possible solutions to the associated conflicts that have arisen as a result of citizenship exclusion at the national and regional levels.

The European Union (EU) has an established tradition of democracy and fundamental rights protection for its citizens. However, the Copenhagen criteria, which define the rules under which nations can join EU, also include rules specifically designed to ensure protection of minorities. Furthermore, EU countries are encouraged to assist in the development of institutions which are compatible with the migrants' cultures, identities, practices, and political ideals. From the vantage point of migrants, the concept of democratic "ownership" involves several interrelated facets. Its formal boundaries are regulated by an evolving body of citizenship laws across a myriad of countries. The actual achievement of democratic "ownership", however, is crucially affected by the citizenship ascension decisions, and the political participation choices, made by migrants themselves. Moreover, the above aspects are profoundly influenced by, and indeed largely codetermined with, the natives' responses to non-citizens' participation demands. More generally, it has been recognized that citizenship ascension represents the main avenue to permit migrants' participation and inclusion, since it encourages a sense of belonging in national life and insures potentially active participation in the political, civil, social, economic, and cultural lives of the relevant societies (European Commission 2003).

The core research questions to be examined in this special issue reflect a deep concern for the policy implications and societal impact of citizenship acquisition. Immigrant ascension to citizenship has been traditionally recognized as the apex of the integration process. Conversely, when citizenship ascension was withheld or delayed by the host country, this was traditionally viewed as a statement of hesitation concerning full integration. Thus, the terms and conditions of citizenship acquisition can be argued to be an expression of the host country's ultimate integration policy.

The five papers in this issue examine a broad range of citizenship issues ranging from theoretical and empirical perspectives on EU citizenship, to voter behavior to economic integration.

In the first article of this issue, Christian Fernandez takes up the idea of constitutional patriotism, launched almost 20 years ago, by Jürgen Habermas as a proposed solution to the tension between citizenship and national identity in the EU. Since then, constitutional patriotism has remained a key concept in debates on EU citizenship and democracy. This article, as so many before it, scrutinizes the meaning and viability of the concept. Unlike most others, however, it focuses less on the content of the concept and more on the subjects to which it is assumed/supposed to apply. It argues, firstly, that constitutional patriotism is not a viable or even desirable ideal for the European demos in its totality. The potential patriots of the EU are not the large majority of EU citizens who live in their home country, but migrants from other member states and non-member states who are foreigners in their host countries. Secondly and accordingly, it argues that advancing constitutional patriotism means improving the status of foreign nationals in general and third country nationals in particular. Connecting the acquisition of EU citizenship to domicile as opposed to member state nationality is one venue for such improvement. It finally discusses what this could imply and defend it as a means of building truly European demos.

Constanza Vera Larrucea explores the conceptual changes in the classical understanding of citizenship in connection with marked shifts in citizenship. She 
argues that most of this work has been developed to explore legal and institutional aspects, thus giving citizenship a static framework. By turning to individuals' perceptions, a new picture of citizenship is discovered. She is able to pay attention to a group that has not been central in discussions about citizenship, namely immigrants' descendants or so-called second generation immigrants. This group is regarded as being in between their parents' native country and the country in which they were themselves born, which could result in an ambiguous membership and potentially divided allegiance, especially for those having dual citizenship. In this article, Vera Larrucea introduces the experiences of Turkish descendants in France and Sweden. Qualitative work complemented by survey data shows how dual citizens prioritize one country or both in order to develop new and traditional aspects associated with citizenship. Two dimensions are explored: a civic dimension composed by traditional elements associated with legal status such as rights and duties, and a subjective dimension that is defined by the personal elements that link individuals with the country, city, or community to which they belong.

Guita Hourani and Eugene Sensenig-Dabbous look at political participation and voting behavior in Lebanon. In particular, they examined a 1994 act which granted citizenship to over 200,000 persons en masse by decree. The majority of the naturalized were registered in four main electoral districts: Beirut and the North (mainly Muslim), Maten and Zahle (mainly Christians). Of the newly naturalized, three quarters were Muslim and about a fifth Christian. The process of the naturalization decree was described by some as unconstitutional. This was confirmed by the decision of the State Consultative Council in 2003 which invalidated the 1994 decree. The impact of the naturalization decree tipped the demographic balance in some districts reinforcing electoral support for certain officials. In this article, they explore the degree to which these newly naturalized citizens voted in the elections of 1996, 2000, 2005, and 2007, how they voted and whether their voting behavior changed the outcome of the election in certain parts of the country.

Articles by Pieter Bevelander and Ravi Pendakur, and Max Steinhardt and Jan Wedemeier look at the labor force outcomes of citizenship acquisition. Using data drawn from the 2006 Swedish registry, Bevelander and Pendakur employ instrumental variable regression to examine the "clean" impact of citizenship acquisition and the size of the co-immigrant population on the probability of being employed. They find that citizenship acquisition has a positive impact for a number of immigrant groups. This is particularly the case for non-EU/non-North American immigrants. In terms of intake class, refugees appear to experience substantial gains from citizenship acquisition (this is not, however, the case for immigrants entering as family class).

Steinhardt and Wedemeier examine the integration prospects of immigrants in Switzerland. They focus on the distinction between naturalized and non-naturalized immigrants. The comparison on the basis of the 2008 wave of the Swiss Labor Force Survey is motivated by findings in the literature that highlight the role of citizenship in the integration process. They demonstrate that naturalized employees tend to have higher wages and lower unemployment rates than non-naturalized immigrants. An applied Blinder-Oaxaca decomposition technique demonstrates that this is strongly connected to higher human capital endowments of immigrants who attained Swiss nationality. The findings therefore highlight previous findings from other countries 
stating that immigrants positively select into citizenship. However, there remains an unexplained part of the wage gap between the two groups which indicates that the acquisition of citizenship might increase the labor market opportunities of migrants.

\section{Reference}

European Commission (2003) Proposal for a council decision establishing a community action programme to promote active European citizenship (civic participation), 2003/0116 (CNS). 